\title{
The effect of glycerol on signal supression during electrospray ionization analysis of proteins
}

\author{
M.A. Mendes ${ }^{\mathrm{a}, \mathrm{b}}$, B.M. Souza ${ }^{\mathrm{a}, \mathrm{b}}$, M.R. Marques ${ }^{\mathrm{a}, \mathrm{b}}$ and M.S. Palma ${ }^{\mathrm{a}, \mathrm{b}, *}$ \\ ${ }^{a}$ Laboratory of Structural Biology \& Zoochemistry, CEIS/Dept. Biology, Institute of Biosciences, \\ UNESP, Rio Claro, SP-Brazil \\ ${ }^{\mathrm{b}}$ Institute of Immunological Investigations (MCT/CNPq)
}

\begin{abstract}
The effect of salts, detergents and chaotropic agents on mass spectrometric analysis are relatively well understood, mainly due to their actions decreasing the performance of ESI interface in mass spectrometric analysis. However, there are few studies in the literature characterizing the effect of protein stabilization by glycerol, followed in some circumstances by the suppression of protein signal when ESI interface is used. The aim of the present research was to investigate in details the mass spectrometric behavior of some proteins in presence of high levels of glycerol during ESI-MS analysis. Thus, horse heart myoglobin and chicken ovalbumin were used as standard proteins. It was demonstrated that the presence of $1 \%(\mathrm{v} / \mathrm{v})$ glycerol suppressed the signal of these proteins during the ESI-MS analysis, even when the sample nozzle potential was scanned from 28 to $80 \mathrm{~V}$. However, when the glycerol concentration was decreased to $0.5 \%(\mathrm{v} / \mathrm{v})$ and the sample cone voltage adjusted to $50 \mathrm{~V}$, a perfect envelope of peaks was observed, allowing the spectrum deconvolution and the molecular mass determination with mass accuracy lower than $0.01 \%$ in each situation. A molecular explanation for this suppressive effect and for the analytical overcoming of this difficult is proposed.
\end{abstract}

\section{Introduction}

Electrospray ionization (ESI) mass spectrometry (MS) is a rapid and precise method for determining masses of proteins and can be used to validate protein sequences [1]; in addition to this it may be used as an important technique to evaluate the protein purity/homogeneity. The mass accuracy of ESI-MS is generally within the limit from $0.01 \%$ to $0.05 \%$ of the calculated masses [1,2] and has been used to characterize many recombinant proteins $[3,4]$. ESI-MS also may be used to characterize unusual posttranslational modifications [5], and also to identify errors in cDNA sequences [6].

Many commercial recombinant proteins used as molecular biology tools, and even some of those academically-made preparations are maintained in presence of high glycerol concentrations after purification to keep stable the biological activity.

Methods for cloning, direct sequencing, clinical diagnosis and many other uses [7], have proliferated with the current ability to produce from microgram to milligram quantities of particular proteins. Thus, commercial insulin, growth hormone, cytokines [8], DNA polymerases [9] and different types of

\footnotetext{
*Corresponding author: Mario Sergio Palma, Lab. Structural Biology and Zoochemistry - CEIS/IBRC-UNESP Avenue 24A 1515, Bela Vista, Rio Claro, SP- Brazil, CEP 13506-900; E-mail: mspalma@ rc.unesp.br.
} 
restriction enzymes, among other recombinant proteins, have been used as therapeutic proteins and/or commercial biochemicals.

The proteins resulting from these protocols generally are submitted to sodium dodecyl sulfate polyacrylamide gel electrophoresis as the only criteria to check the homogeneity of the preparations. However, some of these proteins may present different molecular forms [10], caused by post-translational modification or even may suffer artifactual proteolytic cleavage [10,11]. Taking into account the ratio standard error of the electrophoretic methods small MW changing may become masked by this procedure.

The effect of many salts, detergents and chaotropic agents are relatively well documented in the decreasing of performance of ESI-MS protocols [12,13]. However, there are a few studies in the literature characterizing the effect of protein stabilization by glycerol, followed in some circumstances by the suppression of protein signal when ESI-MS interface was used [14].

Recently, we described the suppression of protein signal during ESI-MS analysis of recombinant Taq polymerase in presence of $25 \%(\mathrm{v} / \mathrm{v})$ glycerol [9].

Therefore, due to the biotechnological interest in the molecular characterization of natural and/or recombinant proteins, specially related to the control of quality of protein preparations under experimental conditions more close to the industrial requirements, we decided to perform a more detailed investigation about this subject. Thus, myoglobin and ovalbumin were used as standard proteins for ESI-MS analysis in presence of different glycerol concentrations. It was confirmed the suppressive effect of glycerol on ESI-MS signal during the analysis of these standard proteins and proposed a mechanistic model to explain this suppressive effect. In addition to this it was developed a simple and easy strategy to overcome this difficulty, like the use of an appropriate setting up of skimmer for each situation.

\section{Material and methods}

All the solvents used (HPLC grade) were purchased from Mallinckrodt. Glycerol was acquired from Sigma Chem. Co. Bidistilled and ultra purified water used in all experiments was prepared in a Barnsted system.

\subsection{Proteins}

Ovalbumin from chicken egg (grade III) and Mioglobin from horse heart were purchased from Sigma Chem. Co. and used as standard proteins in all mass spectrometric experiments.

\subsection{Mass spectrometry analysis}

The molecular mass determinations were performed by mass spectrometry using some adaptations to the system described by Chassaigne and Lobinski [15]. Samples were dissolved in 50\% (v/v) acetonitrile [containing $0.1 \%(\mathrm{v} / \mathrm{v})$ TFA] and analyzed on a triple quadrupole mass spectrometer Micromass (Altrinchan), model QUATTRO II, equipped with a standard electrospray probe, adjusted to ca $5 \mu \mathrm{l} / \mathrm{min}$. During all experiments the source temperature was maintained at $80^{\circ} \mathrm{C}$ and the needle voltage at $3.6 \mathrm{kV}$, applying a drying gas flow (nitrogen) of $200 \mathrm{l} / \mathrm{h}$ and a nebulizer gas flow of $15 \mathrm{l} / \mathrm{h}$. The mass spectrometer was calibrated with intact horse heart myoglobin and its typical cone-voltage induced fragments.

The cone sample to skimmer lens voltage controlling the ion transfer to mass analyzer was manually scanned from 30 to $130 \mathrm{~V}$. About $50 \mathrm{pmol}$ of each sample was injected into electrospray transport 
solvent. The ESI spectra were obtained in the continuous acquisition mode; scanning from $\mathrm{m} / z 500$ to 2500 at scan time of $7 \mathrm{~s}$. The mass spectrometer data acquisition and treatment system was equipped with Mass Lynx and Transform software for handling and deconvoluting spectra.

\section{Results and discussions}

When 50 pmoles of the fresh protein preparation was diluted in acetonitrile to produce a concentration of $50 \%(\mathrm{v} / \mathrm{v})$ of the solvent, in presence of $1 \%(\mathrm{v} / \mathrm{v})$ glycerol, no ESI-MS signal was observed (Fig. 1c). In fact, no setting up of the instrument was enough to permit the visualization of the envelope of peaks characteristic of proteins during the ESI-MS analysis under this specific experimental conditions.

a

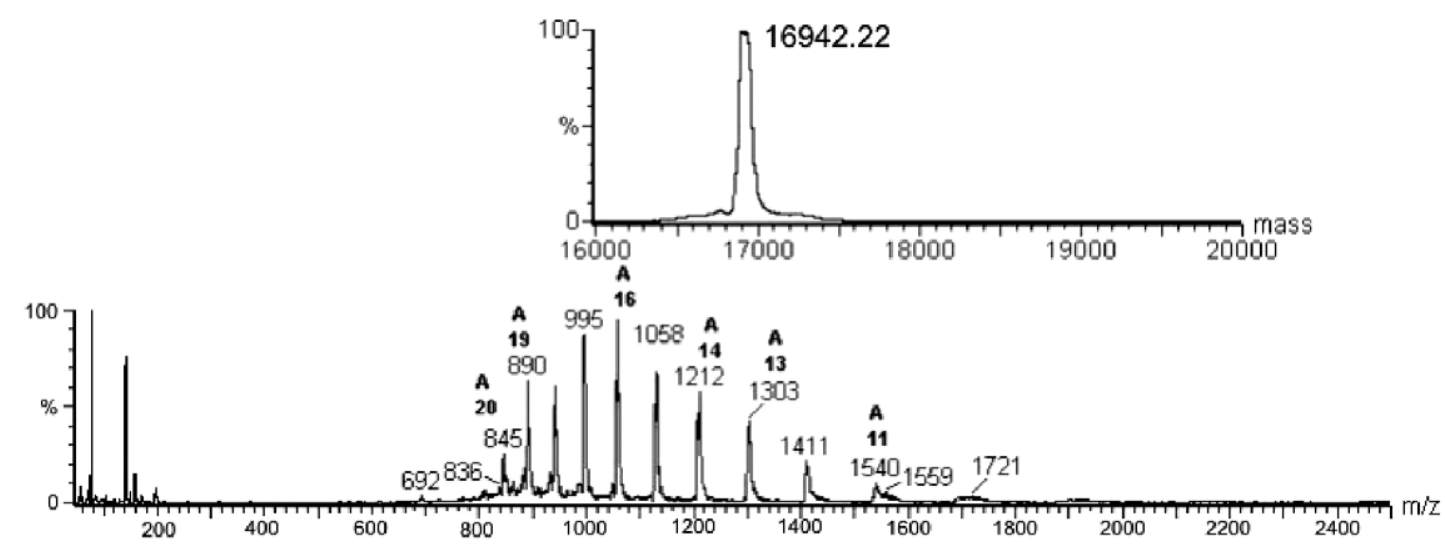

b

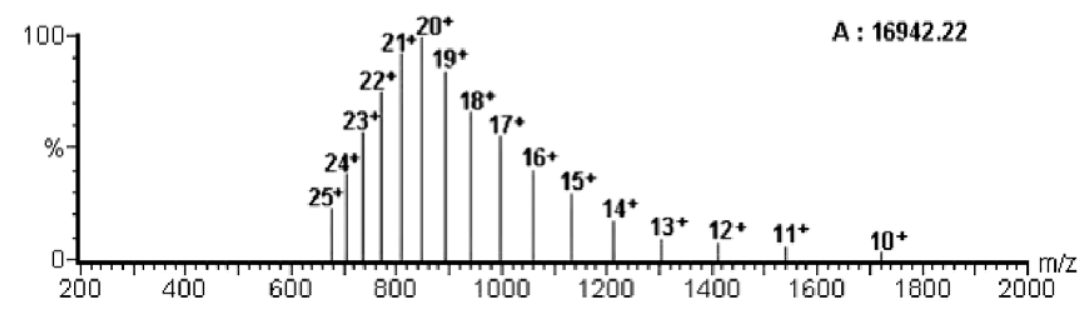

c

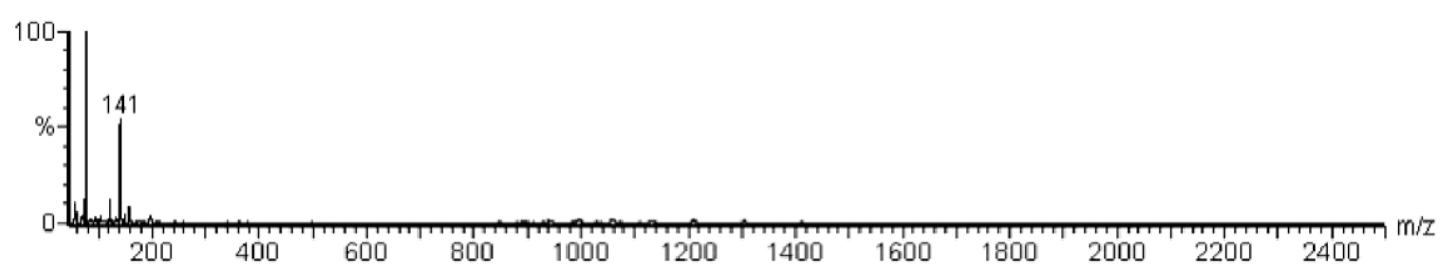

Fig. 1. (a) - ESI-MS spectrum of myoglobin in presence of $0.5 \%(\mathrm{v} / \mathrm{v})$ of glycerol and using a cone sample voltage of $50 \mathrm{~V}$; (b) - centroid mass spectrum representation of the ESI-MS spectrum above; (c) - ESI mass spectrum of myoglobin in presence of $1 \%(\mathrm{v} / \mathrm{v})$ glycerol and using a cone sample voltage of $50 \mathrm{~V}$. 
However, when the analysis was performed in presence of $0.5 \%(\mathrm{v} / \mathrm{v})$ glycerol and by using $50 \%(\mathrm{v} / \mathrm{v})$ acetonitrile [containing $0.1 \%$ (v/v) TFA] as solvent, at a cone sample voltage of $50 \mathrm{~V}$ it was obtained an envelope of peaks from $m / z 692$ to 1721 (Fig. 1a).

The resulting series of peaks in this envelope correspond to ionized myoglobin molecule populations presenting from 10 to 25 positive charges (Fig. 1b). This result is suggesting that under these specific experimental conditions, probably the glycerol molecules are not interacting so strongly with the side chain of the amino acids residues of myoglobin, since it was expected about 31 ionizing basic groups working in the positive mode of ESI interface. This means that only $19 \%$ of basic amino acid residues were prevented to ionize by effect of glycerol in this experimental condition.

Figure 2 show the results of a similar series of experiments performed with the protein ovalbumin. Figure 2c shows the ESI-MS spectrum obtained in presence of $1 \%(\mathrm{v} / \mathrm{v})$ glycerol and by using $50 \%$ $(\mathrm{v} / \mathrm{v})$ acetonitrile [containing $0.1 \%(\mathrm{v} / \mathrm{v}) \mathrm{TFA}$ ] as solvent. In fact, no envelope of peaks may be observed, except a few noisy signals spread from $m / z 894$ to 1959. The scanning of the potential applied to the sample cone from 28 to $80 \mathrm{~V}$ does not change the result showed in Fig. 2c. However, when the experiment was carried out in presence of $0.5 \%(\mathrm{v} / \mathrm{v})$ glycerol and the potential of skimmer adjusted to $50 \mathrm{~V}$, the envelope of peaks characteristic of the spectrum of proteins analyzed with ESI interface was observed from $\mathrm{m} / z 762$ to 1876 , centered on $\mathrm{m} / z 1144$ (Fig. 2a). The centroid representation of this spectrum is showed in Fig. 2b; the resulting series of peaks in this envelope correspond to ionized ovalbumin molecule populations presenting from 26 to 46 positive charges. As already was also observed for myoglobin, this result suggests that the decreasing on glycerol concentration to $0.5 \%$ (v/v) and adjusting the sample cone potential to $50 \mathrm{~V}$ may be used as strategy to overcome the ESI-MS signal suppression in presence of the stabilizing agent.

The transformation of the ESI-MS spectrum obtained at $50 \mathrm{~V}$, in presence of $0.5 \%(\mathrm{v} / \mathrm{v})$ glycerol, revealed an accurate molecular mass of 16,942.22 Da for the myoglobin (Fig. 1a), which is very close to the calculated value from the hypothetical primary sequence of this protein (16,943.86 Da) [16]. The transformation of the ESI-MS spectrum of the ovalbumin revealed an accurate molecular mass of 43,563.45 Da, which is 92 mass units higher than the hypothetical value expected for this protein $(43,471.23 \mathrm{Da})$ [17]; apparently this result suggests the formation of a cluster between one molecule of ovalbumin and one molecule of glycerol (MW $92 \mathrm{Da}$ ).

Thus, the experimental strategy proposed above to overcome the signal suppression caused by the presence of high levels of glycerol during the analysis was successful and, in spite of the use of high voltage level in the sample cone, apparently it was not observed protein fragmentation, since the experimental values determined for the molecular masses of each protein fit the hypothetical ones with very high accuracy.

\section{Conclusions}

The addition of glycerol after the final purification step both for natural and recombinant proteins has the purpose to prevent these molecules from denaturation [14]. However, in spite the stabilizing effect over protein molecules, high level of glycerol influences strongly the mass spectrometric performance under this experimental condition. Generally, in the absence of glycerol the basic and/or acid side chain of the amino acid residues get ionized in presence of water, depending on the $\mathrm{pH}$ of the protein solution (Fig. 3a). When the proteins are analyzed under these conditions by using ESI interface, the typical envelope of peaks can be observed. However in presence of glycerol, this compound displaces the water 

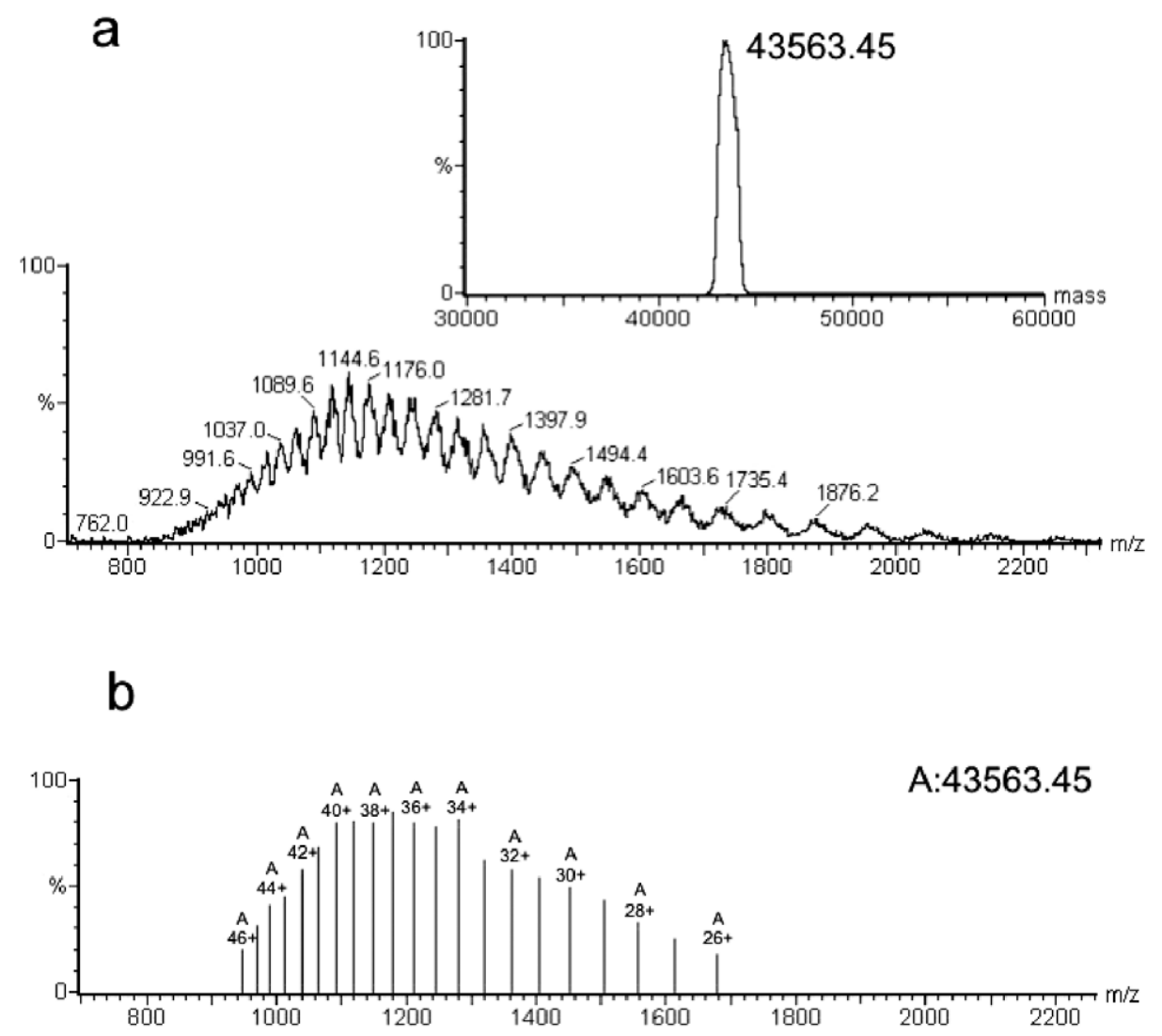

\section{C}

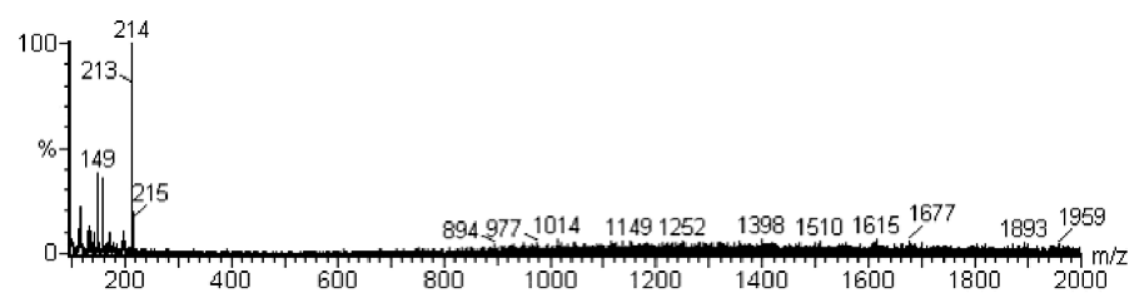

Fig. 2. (a) - ESI mass spectrum of ovalbumin in presence of $0.5 \%(\mathrm{v} / \mathrm{v})$ glycerol and using a cone sample voltage of $50 \mathrm{~V}$; (b) - centroid mass spectrum representation of the ESI-MS spectrum above; (c) - ESI mass spectrum of ovalbumin in presence of $1 \%(\mathrm{v} / \mathrm{v})$ glycerol and using a cone sample voltage of $50 \mathrm{~V}$.

molecules from the protein surface, and establishes itself interactions with side chain groups of amino acid residues, preventing their ionization and suppressing the protein signal (Figs $3 \mathrm{~b}$ and $3 \mathrm{c}$ ), resulting in a flat and noisy base line, like the result showed in the Figs 1c and 2c. Other authors also described that protein samples containing high glycerol concentrations are not amenable to ESI interfaces [14].

A possible explanation for this effect may be the strong interactions between glycerol molecules and the polar sites of the side chain of the amino residues from the proteins. In fact, these interactions may be due to the hydrogen bonds between glycerol molecules and the atoms of hydrogen of the amino/imino 


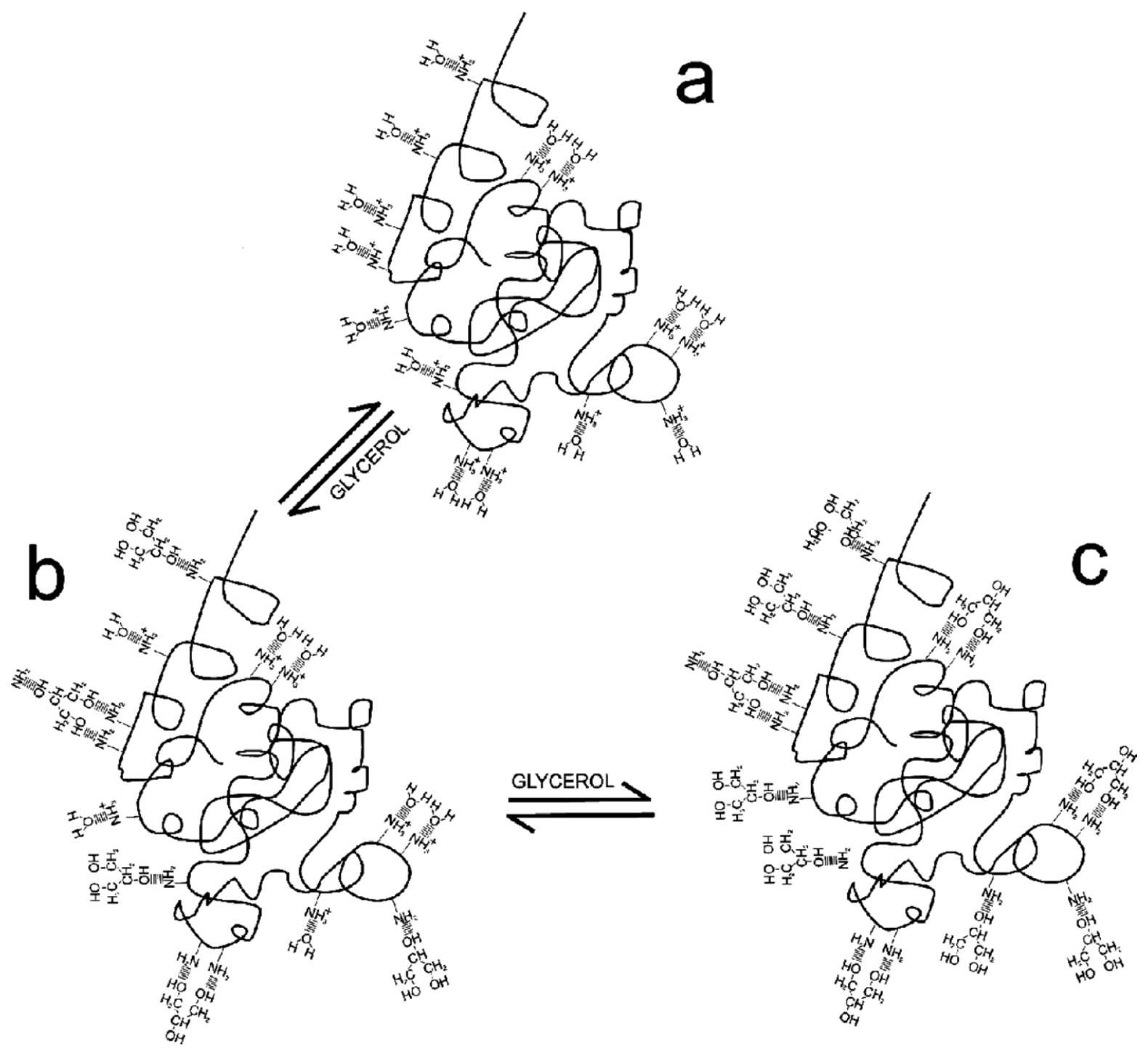

Fig. 3. Scheme showing the shielding effect caused by glycerol in an aqueous solution of proteins: (a) - protein presenting all its protonated basic and acidic residues ionized; (b) - protein in presence of low concentration of glycerol, showing some protonated residues interacting with water molecules, while some other residues are prevented to ionize due to the interaction with glycerol; (c) - protein in presence of high concentration of glycerol, which displaces water molecules from the protein surface, creating the shielding effect.

groups from the basic amino acid residues; also the hydroxyl hydrogen from the acidic amino acid residues may attend this type of interaction.

Glycerol molecules in turn, also may interact with water molecules through hydrogen bonds, probably preventing the direct contact between amino acid side chains and solvation water. In fact, the shielding effect caused by glycerol prevents the proton exchanging between the water and the protein molecules, resulting in the absence of ionization of the amino acid residues side chains [9].

A simple adjustment of the voltage of cone sample from the usual setting of $28 \mathrm{~V}$ to $50 \mathrm{~V}$ probably created an electric field that displaced the glycerol molecules from the direct contact with the 
proteins, permitting to the amino acid residues side chains to get contact with water molecules, becoming temporarily ionized while maintained the high cone voltage. A general schedule summarizing this hypothesis is showed in the Fig. 3.

\section{Acknowledgements}

This work was supported by grants from FAPESP (CAT/CEPID and SMOLBNET), Instituto do Milênio (CNPq/MCT), PICR/PROPP-UNESP and Sinc do Brasil; MAM is post-doc Fellow of FAPESP; MSP is researcher of the National Research Council (CNPq, 500079/90-0).

\section{References}

[1] D.S. Ashton, C.R. Beddell, B.N. Green and R.W.A. Oliver, Rapid validation of molecular structures of biological samples by electrospray mass spectrometry, FEBS Lett. 342 (1994), 1-6.

[2] B.T. Chait and B.H Kent, Weighing naked proteins: practical, high-accuracy mass measurement of peptides and proteins, Science 257 (1992), 1885-1894.

[3] M. Pedrocchi, B.W. Schafer, I. Durussel, J.A. Cox and C.W. Heizmann, Purification and characterization of the recombinant human calcium-binding S100 proteins CAPL and CACY, Biochemistry 33 (1994), 6732-6738.

[4] U.G. Fohr, C.W. Heizmann, D. Engelkamp, B.W. Schafer and J.A. Cox, Purification and cation binding properties of the recombinant human S100 calcium-binding protein A3, an EF-hand motif protein with high affinity for zinc, J. Biol. Chem. 270 (1995), 21056-21061.

[5] M.J. Raftery, C.A. Harrison, P. Alewood, A. Jones and C.L. Geczy, Isolation of the murine S100 protein MRP14 (14 $\mathrm{kDa}$ migration-inhibitory-factor-related protein) from activated spleen cells: characterization of post-translational modifications and zinc binding, Biochem. J. 316 (1996), 285-293.

[6] M.J. Raftery and C.L. Geczy, Identification of posttranslational modifications and cDNA sequencing errors in the rat $\mathrm{S} 100$ proteins MRP8 and 14 using electrospray ionization mass spectrometry, Anal. Biochem. 258 (1998), 285-292.

[7] S.M. Innis, K.D. Foote, M.J. MacKinnon and D.J. King, Plasma and red blood cell fatty acids of low-birth-weightinfants fed their mother's expressed breast milk or preterm-infant formula, Am. J. Clinical Nutrition 51 (1990), 994-1000.

[8] J.L. Cleland, Impact of protein folding on biotechnology, in: Protein Folding in Vivo and in Vitro, J.L. Cleland, ed., American Chemical Society, Washington, DC, 1993, pp. 1-21.

[9] M.A. Mendes, J.M. Chies, A.C. de Oliveira Dias, S.A. Filho and M.S. Palma, The shielding effect of glycerol against protein ionization in electrospray mass spectrometry, Rapid Commun. Mass Spectrom. 17 (2003), 672-677.

[10] A. Chien, D.B. Edgar and J.M. Trela, Deoxyribonucleic acid polymerase from the extreme thermophile Thermus aquaticus, J. Bacteriol. 127 (1976), 1550-1557.

[11] A.S. Kaledin, A.G. Slyusarenko and S.I. Gorodetskii, Isolation and properties of DNA polymerase from extreme thermophylic bacteria Thermus aquaticus YT-1, Biokymiya 454 (1980), 644-651.

[12] S. Canarelli, I. Fisch and R. Freitag, On-line micro dialysis of proteins with high-salt buffers for direct coupling of electrospray ionization mass spectrometry and liquid chromatography, J. Chromat. A 948 (2002), 139-149.

[13] C.L. Liu, S.A. Hofstadler, J.A. Bresson, H.R. Udseth, T. Tsukuda, R.D. Smith and A.P. Snyder, Anal. Chem. 70 (1998), 1797.

[14] R. Grandori, I. Matecko, P. Mayr and N. Müller, Probing protein stabilization by glycerol using electrospray mass spectrometry, J. Mass Spectrom. 36 (2001), 918-922.

[15] H. Chassaigne and R. Lobinski, Characterization of horse kidney metallothionein isoforms by electrospray MS and reversed-phase HPLC-electrospray MS, Analyst 123 (1998), 2125-2130.

[16] C.L. Hunter, R. Maurus, M.R. Mauk, H. Lee, E.L. Raven, H. Tong, N. Nguyen, M. Smith, G.D. Brayer and A.G. Mauk, Introduction and characterization of a functionally linked metal ion binding site at the exposed heme edge of myoglobin, Proc. Natl. Acad. Sci. USA 100 (2003), 3647-3652.

[17] P.E. Stein, A.G. Leslie, J.T. Finch and R.W. Carrell, Crystal-structure of uncleaved ovalbumin at 1.95 A resolution, J. Mol. Biol. 221 (1991), 941-959. 


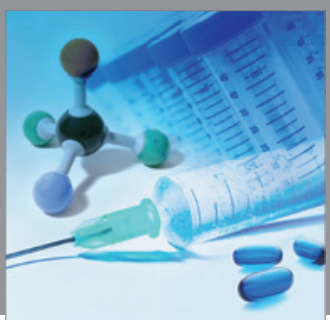

International Journal of

Medicinal Chemistry

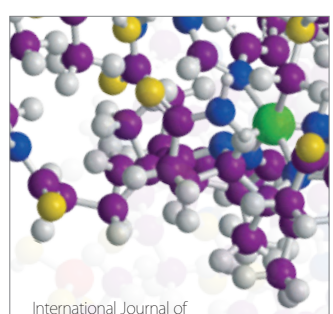

Carbohydrate Chemistry

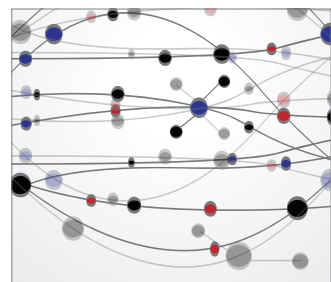

The Scientific World Journal
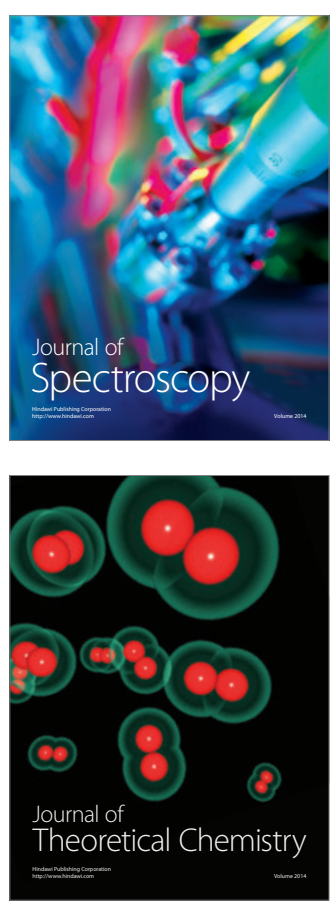
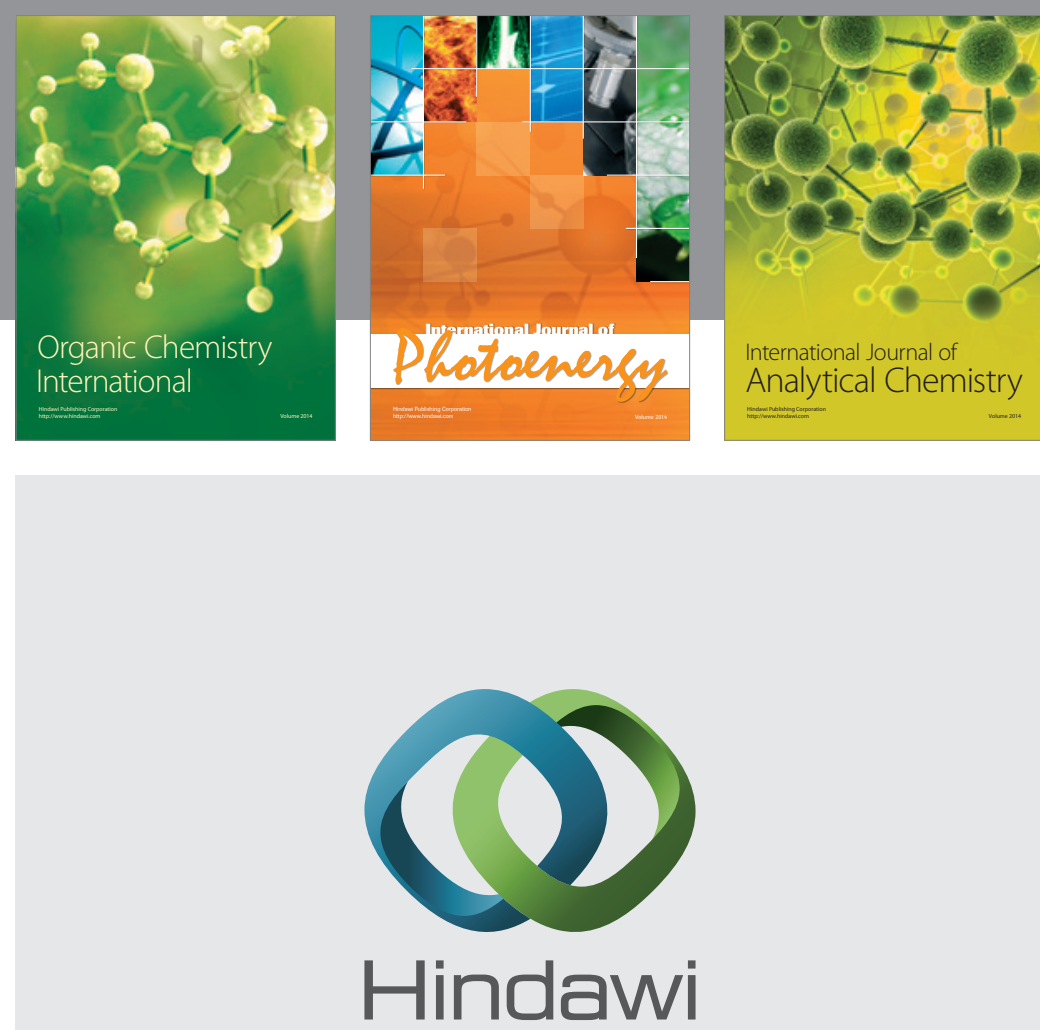

Submit your manuscripts at

http://www.hindawi.com
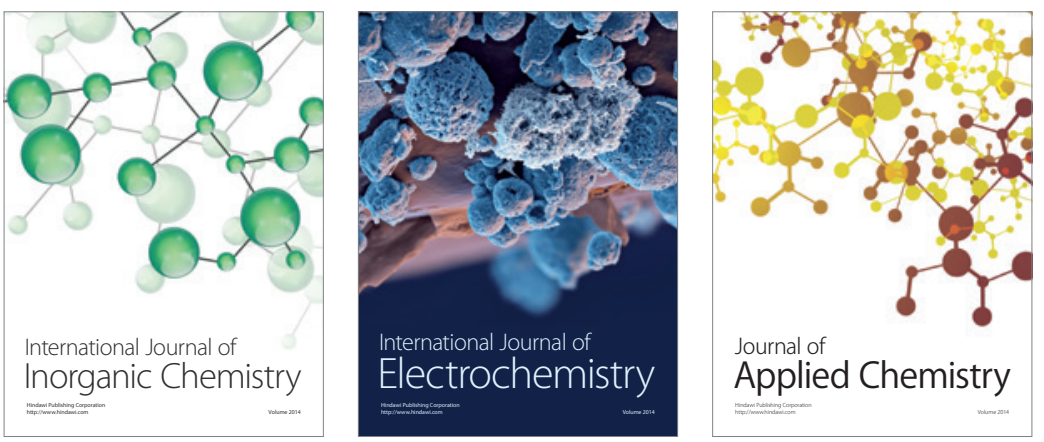

Journal of

Applied Chemistry
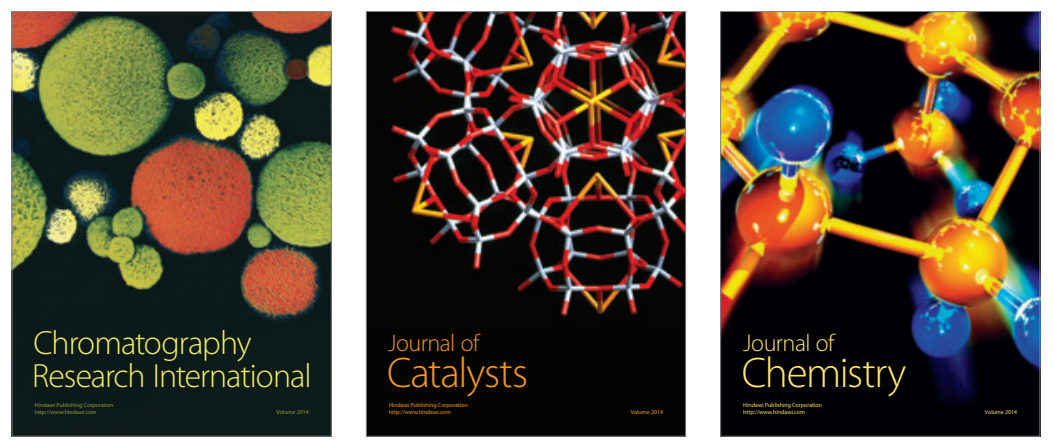
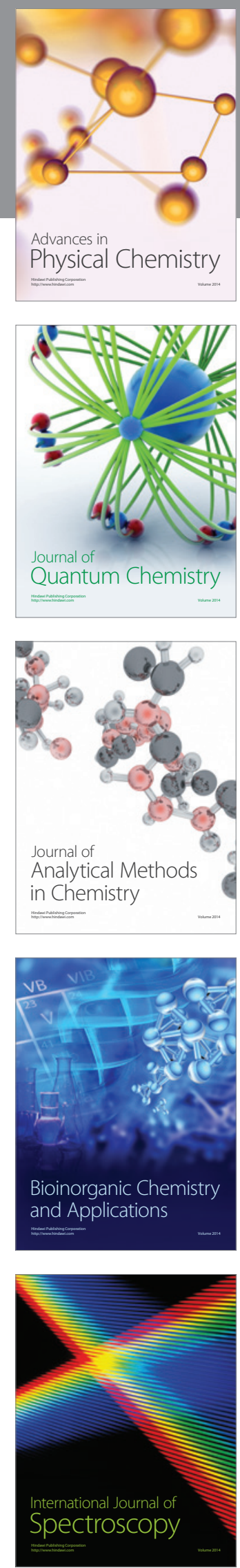